DOI 10.15593/2224-9354/2017.2.16

УДК 330.332

\author{
О.В. Буторина, И.В. Шишкина
}

\title{
ИНВЕСТИЦИОННАЯ ПРИВЛЕКАТЕЛЬНОСТЬ КОМПАНИИ: СУЩНОСТЬ, СОПОСТАВЛЕНИЕ МЕТОДИК ОЦЕНКИ
}

\begin{abstract}
Представлена авторская трактовка понятия «инвестиционная привлекательность компании», на основании которой выделены методики ее анализа в отечественной и зарубежной теории и практике управления инвестиционными процессами. При сопоставлении пятнадцати методик анализа инвестиционной привлекательности были выделены показатели для количественной и качественной оценок, а также их достоинства и недостатки с точки зрения внешних и внутренних условий функционирования предприятий в современной России. Апробация наиболее интересных из них с соответствующими расчетами для компаний, производящих электротехническое оборудование, позволила сделать выводы: 1) о необходимости их комплексного использования; 2) о целесообразности расчета интегрального показателя инвестиционной привлекательности в качестве результирующего параметра при принятии инвестиционного решения; 3) о значимости использования при расчетах эталонных значений; 4) о необходимости корректировки и дополнения количественных и качественных показателей, характеризующих в динамике базовые процессы деятельности предприятия; 5) о целесообразности учета интереса всех участников инвестиционной деятельности: инвестора, инвестируемого, финансового посредника. Полученные выводы, как нам представляется, могут быть интересны с точки зрения теории и практики управления инвестиционной привлекательностью предприятий, регионов, несмотря на всю их неоднозначность.

Ключевые слова: инвестиционная привлекательность, инвестиционная привлекательность предприятий, внешние и внутренние факторы инвестиционной привлекательности предприятий. сопоставление методик оценки инвестиционной привлекательности предприятия, интегральный показатель инвестиционной привлекательности предприятия.
\end{abstract}

В современных условиях усиливается конкуренция между предприятиями за рынки сбыта, за ресурсы, за государственные заказы и бюджетное финансирование, как следствие, для оптимизации своего положения в рыночном пространстве компании должны совершенствоваться, осваивать новые виды продукции и технологии, расширять виды деятельности, поддерживать свою конкурентоспособность и решать вопросы увеличения стоимости своего бизнеса. В этих условиях актуализируются проблемы обеспечения притока инвестиций. Привлечение инвестиций позволяет компании наращивать конкурентные преимущества и формировать дополнительные ресурсы для прогрес-

(C) Буторина О.В., Шишкина И.В., 2017

Буторина Оксана Вячеславовна - канд. экон. наук, доцент кафедры экономики и финансов ФГБОУ ВО «Пермский национальный исследовательский политехнический университет», доцент кафедры мировой и региональной экономики, экономической теории ФГБОУ ВО «Пермский государственный национальный исследовательский университет», e-mail: ok.butorina@yandex.ru.

Шишкина Ирина Викторовна - ст. преподаватель кафедры мировой и региональной экономики, экономической теории ФГБОУ ВО «Пермский государственный национальный исследовательский университет», e-mail: irvik-59@mail.ru. 
сивного экономического развития. Как известно, привлечение инвестиций направлено на наращивание эффективности функционирования предприятий, как следствие, стоимости компаний.

На основании представленных положений актуальности управления инвестиционной привлекательностью предприятий в современной российской практике может быть сформулирована цель данной публикации. Она заключается в обосновании комплексного использования различных методик оценки инвестиционной привлекательности предприятия, учитывающей интересы всех субъектов инвестиционного процесса.

Данная цель определила необходимость последовательного решения следующих задач:

- предложить авторскую трактовку понятия инвестиционной привлекательности предприятия;

- представить краткую характеристику методик оценки инвестиционной привлекательности в зарубежной и отечественной теории и практике;

- апробировать наиболее значимые из методик, предполагающие расчет интегрального показателя трех предприятий электротехнической отрасли для разработки рекомендаций дальнейшего совершенствования оценки инвестиционной привлекательности, учитывающей интересы всех участников.

Под инвестиционной привлекательностью понимается интегральная величина, характеризующаяся не только платежеспособностью, устойчивостью финансового состояния предприятия, а также эффективностью использования его имущества, способностью к саморазвитию за счет наращивания доходности капитала, технико-экономического содержания производства, роста качества и конкурентоспособности продукции. Исходя из этого, инвестиционная привлекательность предприятия - это комплексный показатель, количественно определяющий целесообразность инвестирования средств в конкретное предприятие [1, с. 4].

Е.А. Суркова определяет инвестиционную привлекательность как некий критерий оценки эффективности капиталовложений в различные объекты при наличии альтернативных вариантов размещения ресурсов [1]. На основании чего инвестиционная привлекательность предприятия может рассматриваться как параметр целесообразности вложения в него временно свободных денежных средств.

В настоящее время четко сформировались базовые инструменты финансирования деятельности предприятий. Самыми распространенными способами привлечения инвестиций являются:

1) кредиты и займы;

2) формирование инвестиций через дополнительные вклады учредителей;

3) средства стратегического инвестора. 
Использование кредитов и займов позволяет в кратчайшие сроки аккумулировать инвестиционные ресурсы, но определение кредитором объема, срока, их стоимости делает данный способ по сравнению с другими более дорогим. При этом неотъемлемым условием получения займов и кредитов является высокий уровень платежеспособности или высокая стоимость залогового имущества.

Оставшиеся два способа привлечения инвестиций (формирование инвестиций на фондовом рынке и средства стратегического инвестора) также требуют от предприятий прозрачности бизнеса, открытой отчетности. При этом, чем выше инвестиционная привлекательность предприятия на данном рынке, тем выше возможности привлечения инвестиции.

Необходимо учитывать также тот факт, что каждый инвестор при определении объектов инвестирования преследует свои цели. В зависимости от них инвесторов можно разделить на две группы.

Первая группа - инвесторы финансового типа, которые стремятся к максимизации стоимости компании на основе обеспечения наибольшей прибыли в момент выхода из проекта.

В современной России инвестиционные компании и фонды, прежде всего фонды венчурных инвестиций реализуют себя как финансовые инвесторы, которые получают прибыль с дивидендов или купонов, выплачиваемых компанией, а также с роста курса ценных бумаг предприятия.

Вторая условно выделенная группа инвесторов - это инвесторы стратегического типа, которые стремятся получить дополнительные выгоды от капиталовложений, активно участвуют в управлении объектом инвествложений. Обычно в качестве стратегического инвестора в условиях современной России выступает компания, деятельность которой непосредственно связана с бизнесом компании, в которую инвесторы вкладываются.

В настоящее время используется система параметров, которая позволяет определить финансовое состояние и рассчитать инвестиционную привлекательность предприятия. При этом оценка инвестиционной привлекательности должна быть произведена как на основе анализа документов финансовой отчетности предприятия и внеучетной информации о предприятии, что формирует системность в изучении макро- и микроэкономических факторов: отнесение предприятия к конкретным отраслям (отрасли, находящиеся в фазах кризиса и депрессии или в фазах оживления и подъема) или территориям (как известно, и регион, и федеральный округ могут обладать различной степенью инвестиционной привлекательности).

Такой комплексный анализ позволяет потенциальному инвестору выделить те предприятия, которые имеют большие потенции последующего перспективного развития в средне-, долгосрочной перспективах и позволят инвестору получить планируемую прибыль с вложенного капитала при имеющихся рисках. 
Таким образом, каждое предприятие как объект инвестиционного рынка характеризуется собственным уровнем инвестиционной привлекательности и одновременно зависит от уровня инвестиционной привлекательности вышестоящей системы. Как следствие, принимая решение о финансировании проекта, необходимо определить влияние множества факторов, формирующих доходность инвестиционных вложений. Учитывая разные варианты различных значений этих факторов, инвестор оценивает их аккумулированное влияние, т.е. инвестиционную привлекательность социально-экономической системы в целом $[1$, с. 12]. Исходя из чего возникает необходимость количественной оценки инвестиционной привлекательности предприятия. Как нам представляется, данный показатель должен иметь экономический смысл, что определяет совокупность требований, предъявляемых к методике расчета интегрального показателя инвестиционной привлекательности. По мнению О.Н. Егоровой, такой показатель должен: учитывать для инвестора значимые факторы внешней среды; отражать доходность вложенных средств; быть сопоставимым с ценой капитала [2, с. 29].

Для этого могут быть использованы как статические, так и динамические показатели эффективности инвестиционных проектов. Сформированная с учетом данных требований методика оценки инвестиционной привлекательности предприятий позволит осуществить качественный и обоснованный выбор объекта капиталовложений, определить эффективность инвестиций в случае усиления негативных тенденций развития внешней среды [2].

Практика определения инвестиционной привлекательности насчитывает почти 40 лет. Одними из первых появились исследования инвестиционной привлекательности Гарвардской школы бизнеса. В их основе лежат сопоставления характеристик каждой страны по экспертной шкале, включающей в себя: институциональные условия для иностранных и национальных инвесторов, возможность вывоза капитала, состояние национальной валюты, политическая ситуация, уровень инфляции, возможности использования национального капитала [2, с. 13]. Выбранный экспертами круг показателей не был достаточно детализирован для полного отражения всего комплекса наиболее значимых для инвестора факторов внешней среды. Поэтому дальнейшее развитие методик сравнительной оценки инвестиционной привлекательности стран пошло по пути расширения и усложнения системы параметров, оцениваемых экспертами, и введения количественных (статистических) показателей [2, с. 12].

Исследование ряда методик, анализирующих инвестиционную привлекательность и используемых в отечественной и мировой практике, позволяет сгруппировать их с позиций основных направлений оценки, целей проведения анализа (табл. 1). 
曋

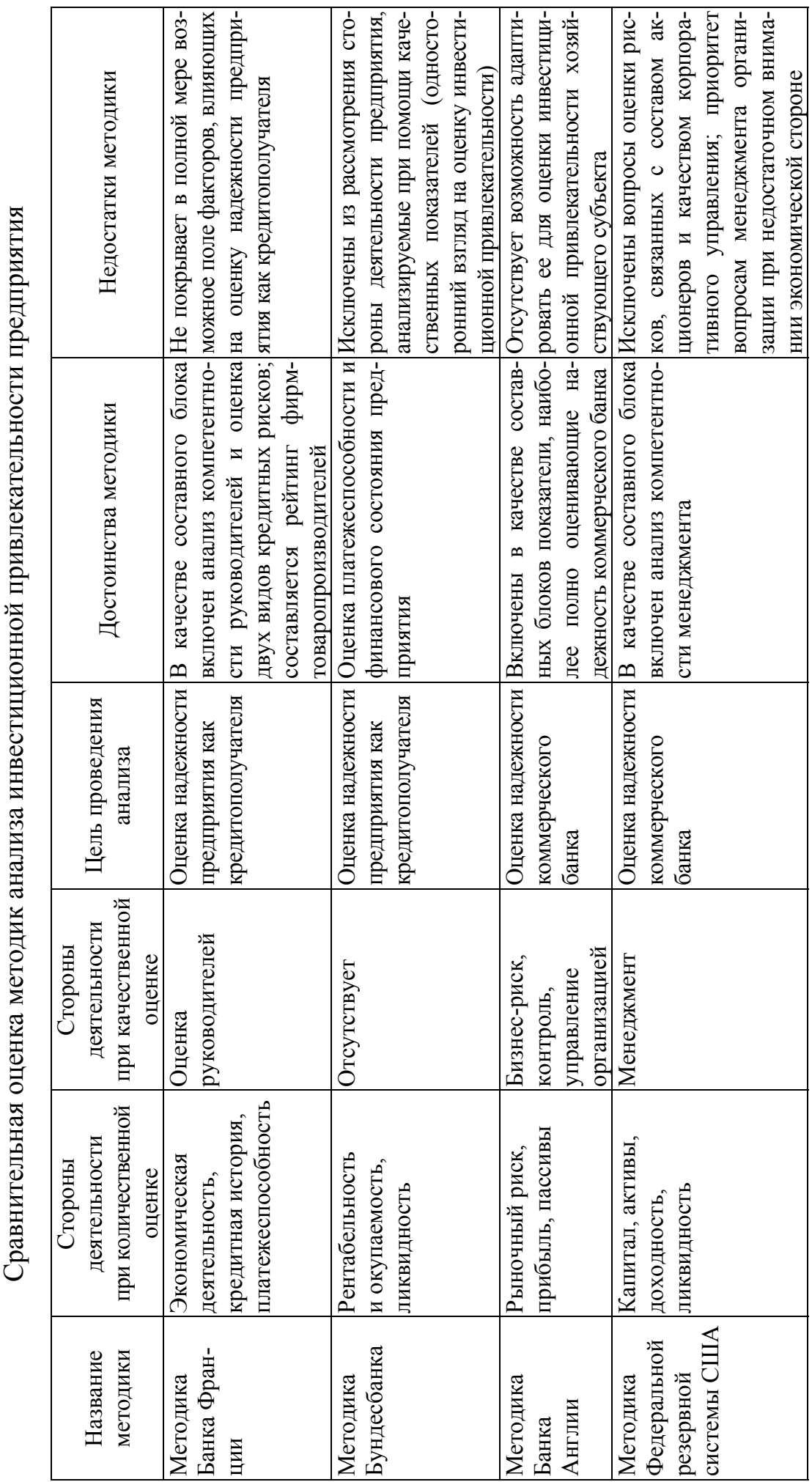


Каждая из них имеет и достоинства, и недостатки при осуществлении комплексной оценки инвестиционной привлекательности для российских предприятий. Более того, эти системы оценки недостаточно ориентированы на развитие инвестиционной деятельности внутри страны. Общим их недостатком является их однонаправленность.

Более актуальными сегодня являются методики Т.В. Федоровича, Ю.В. Севрюгина, Д.А. Ендовицкого, В.А. Бабушкина, И.А. Бланка и др. Далее охарактеризуем основные из них.

Методика Т.В. Федоровича представляет собой анализ следующих параметров: положение компании на рынке, ее деловая репутация, ее зависимости от поставщиков и покупателей, оценка акционерами компании, критерии качества управлением ей [3, с. 29].

Положительными аспектами методики являются простота и понятность; возможность определить, по каким параметрам анализируемая компания не соответствует эталонным значениям. Среди недостатков методики можно отметить тот факт, что методика является базовой, но не исчерпывающей, так как опирается только на ретроспективные показатели.

Балльная оценка в рамках методики Ю.В. Севрюгина [4, с. 28]. Каждому количественному и качественному фактору присваиваются соответствующие баллы (в соответствии с созданным специальным алгоритмом). Интегральный коэффициент инвестиционной привлекательности предприятия рассчитывается по формуле

$$
y=\sum x_{\max }^{x_{i}},
$$

где $i$ - количество факторов; $x_{i}$ - балльная оценка $i$-го фактора с учетом его весомости; $x_{\max }$ - максимально возможное суммарное количество баллов.

Результаты балльной оценки представляют собой некую позицию, аккумулирующую несколько качественных оценок, достигнутую предприятием на рынке. Недостатками такой оценки инвестиционного потенциала предприятия являются: высокий субъективизм, порожденный использованием качественной оценки вклада показателей, а также произвольное суммирование принципиально не суммируемых коэффициентов, прежде всего относительных [5, с. 5]. Данные факторы существенно ограничивают возможности применения методики. Несмотря на это, достоинством данной методики является простота применения.

В методике Д.А. Ендовицкого, В.А. Бабушкина проанализирована роль рыночной капитализации в качестве индикатора инвестиционной привлекательности компании $[6$, с. 20]. Была выявлена гипотеза о влиянии изменения определенных факторов на изменение капитализации и компании, и рынка [6, с. 21].

Индивидуальная оценка параметров инвестиционного потенциала и инвестиционного риска предприятия позволяет наиболее полно определить зна- 
чимость данных факторов при реализации инвестиционного проекта и подход, базирующийся на соотношении доходности и риска, а также характеристике их взаимосвязи. Она определяется на основе расчета таких показателей, как операционный левередж и запас финансовой прочности (зона безопасности), сравнение их фактических значений с нормативными, что может указать предприятию на пути повышения его инвестиционной привлекательности.

Особенностью рейтинговой методики является комплекс показателей с обобщающими критериями и количественной оценкой границ привлекательности и риска на основе понимания предприятия как системы, состоящей из совокупности подсистем. В ходе рейтинговой оценки выделяют наиболее значимые признаки, которые должны быть общими для всех предприятий и отражать важные для инвестора аспекты деятельности оцениваемых предприятий, которые могут быть сопоставлены с аналогичными показателями всех исследуемых предприятий. Для исключения субъективизма на составление рейтинговой оценки каждый рассчитанный показатель предприятия сравнивается с показателями лучшего предприятия, значения которого принимаются за эталон. В качестве эталонных часто используются значения, рекомендованные мировой или российской практикой успешного функционирования предприятия. При этом чем ближе значения рейтинговой оценки к эталонным, тем выше уровень инвестиционной привлекательности. Как показывает практика, метод рейтинговой оценки часто сводится к расчету интегрального показателя, который определяется путем свода числовых значений отдельных показателей инвестиционной привлекательности [7, с. 29]. К недостаткам рейтинговой оценки можно отнести: нивелирование вклада каждого показателя в рейтинг; использование метода «расстояний» для относительных показателей. Результатами рейтинговой оценки является относительный уровень - рейтинг, находящийся в обратной зависимости от кратчайшего расстояния, между эталонным состоянием предприятия на рынке и фактическим. Расстояние рассчитывается как сумма квадратов отклонений фактических уровней нормированных показателей от их эталонных значений [7, с. 29]. Этот вид оценки инвестиционного потенциала заслуживает большего внимания и более предпочтителен по сравнению с предыдущим, так как полученные результаты могут быть проверены с помощью факторного анализа.

Наиболее распространенными в российской практике являются методы, разработанные фирмами Rundt, ICRG, BERI, Frost \& Sullivan, которые позволяют выявить риски потери вложенных средств при влиянии различных факторов. К числу самых известных методов можно отнести системы оценки инвестиционной привлекательности и риска - Institutional Investor, Euromoney, Business Environment Risk Index (BERI) [8, c. 39]. Международные агентства осуществляют рейтинговые оценки в зависимости от уровня кредитоспособности субъекта хозяйствования. При использовании данных методик необходимо учитывать, что, во-первых, большая часть показателей с соответствующей трактовкой разработана для условий стабильной экономики, совершен- 
ной финансовой системы, поэтому для условий транзитивных экономик трактовка данных показателей не всегда корректна. Во-вторых, при оценке инвестиционной привлекательности предприятия весомые значения приобретают «факторы рыночной инфраструктуры» (динамика котировок и объемов продаж акций предприятия, степень развития рыночной инфраструктуры, которая характеризует эффективность использования рыночного инструментария в деятельности предприятия) $[10$, с. 5]. Недостаточный уровень развития финансового рынка, отсутствие прозрачности сделок, высокий риск, низкая эффективность функционирования фондового рынка в России существенно снижают масштабы использования данных методик.

При этом большое значение в условиях низкой осведомленности потенциальных инвесторов на развивающихся рынках приобретает аттракторная модель [10, с. 4]. Аттракторная модель (от лат. attractio - стягивание, притяжение) - описание сущностных черт процесса привлечения инвестиционных ресурсов на основе формирования условий, в которых интересы инвестора и инвестируемого взаимно притягиваются в точке возможного максимального дохода (в аттракторе) [10, с. 4]. Аттракторная модель основана на прямом взаимодействии субъектов инвестиционного процесса (инвестора, инвестируемого и финансового посредника, что конкретизирует зону ответственности за принятое решение). Данная модель позволяет определить перспективы принимаемого инвестиционного решения. Ее основным недостатком является необходимость проведения адаптации для каждой отрасли в целом или каждого предприятия - дифференцированно [10, с. 7].

И.А. Бланк предлагает интегральное использование западных и отечественных методов оценки инвестиционной привлекательности предприятия [11, с. 112]. Его методика базируется на определении стадии жизненного цикла предприятия (прогрессивные фазы обеспечивают эффективное использование вещественных и человеческих ресурсов) и соотнесении ее с оценкой его инвестиционной привлекательности. Однако в условиях негативного инвестиционного климата сложно определить стадию жизненного цикла предприятия и рассчитать эффекты инвестиционного проекта [12, с. 159].

Т.С. Нурбаев предлагает использовать комплексную методику оценки инвестиционной привлекательности предприятия, основанную на исследовании [13, с. 240]:

- внешней среды;

• рыночных позиций (рыночной стоимости акций, объемов произведенной и реализованной продукции, конкурентоспособность предприятия на рынке);

- экспертных оценок финансовых показателей;

- возможных рисков;

- денежных потоков будущих периодов;

- рейтинговых оценок анализируемого предприятия. 
Последовательность анализа по данным направлениям позволяет учесть систему внутренних и внешних факторов, определяющих инвестиционную привлекательность предприятия.

Еще одним способом определения инвестиционной привлекательности компании, особенно при решении вопросов финансирования стратегического развития является расчет экономической добавленной стоимости (EVA), показателя, который может быть интересен как для учредителей компании, так и внешних инвесторов. Если перед инвестором стоит выбор компании, в которую можно вложиться, или формирования инвестиционного портфеля, может быть использована методика оценки стоимости бизнеса сравнительным подходом. Этот же инструмент может использоваться и самим предприятием при определении направлений инвестиционной деятельности и решении вопросов приоритета финансирования, формирования или развития того или иного направления деятельности самой компании.

На основании краткой характеристики существующих методик анализа можно выделить три подхода к оценке инвестиционной привлекательности организации. Первый из них базируется на индикаторах финансово-хозяйственной деятельности и параметрах конкурентоспособности анализируемого предприятия. Второй подход к оценке инвестиционной привлекательности базируется на анализе инвестиционных потенциалов, риска. Третий подход предполагает детальное исследование динамики и структуры стоимости предприятия.

Выделение данных подходов свидетельствует о том, что общепринятой и универсальной методики оценки инвестиционной привлекательности предприятия на сегодняшний день нет. Существующие методики требуют соответствующих корректировок и разработки новых подходов, учитывающих все факторы, которые влияют на уровень инвестиционной привлекательности предприятия как со стороны государства, региона и отрасли, так и со стороны самого предприятия, позволяющие в большей степени рассчитать результирующий показатель.

Как нам представляется, в целях анализа инвестиционной привлекательности конкретного предприятия должна быть использована комплексная методика анализа инвестиционной привлекательности, состоящая из следующих этапов: анализ внешней и внутренней среды, проведение экспертной оценки (отбор системы показателей), ретроспективный анализ финансовых показателей, рейтинговая оценка компании (с помощью выбранных показателей среди предприятий отрасли), определение стоимости бизнеса и показателя EVA. Все это позволит предприятию самому и его инвесторам решить вопросы о целесообразности и размерах.

Рассмотрим некоторые из вышеназванных методик, определив их сильные и слабые стороны и доказывая необходимость разработки универсального интегрального показателя инвестиционной привлекательности. Хотя надо сказать, что для предприятий разных отраслей этот показатель может отличаться значениями некоторых весовых коэффициентов и нормативным значением. 
Проведем сравнительную рейтинговую оценку ООО «ПКФ» с целью определения места предприятия среди компаний-аналогов в интересах инвестора. Цель - среди трех предприятий выявить наиболее и наименее привлекательное из них с точки зрения инвестирования.

За основу возьмем показатели, характеризующие финансовое состояние предприятия (коэффициент оборачиваемости активов, коэффициент рентабельности активов, коэффициент текущей ликвидности, коэффициент автономии, запас финансовой прочности, сила операционного рычага), наиболее явно отражающие инвестиционную привлекательность предприятия как с точки зрения доходности инвестора, так и с точки зрения его рисков.

На основе этих показателей необходимо рассчитать интегральный показатель оценки инвестиционной привлекательности компании. Для этого будем использовать метод расстояний:

$$
K_{\text {ип }}=\sqrt{\sum_{i-1}^{n}\left(1-\frac{X_{i j}}{X_{i e t}}\right)^{2}},
$$

где $K_{\text {ип }}$ - интегральный показатель инвестиционной привлекательности компании; $n$ - количество финансовых коэффициентов, участвующих в расчете; $X_{i j}$ - значение финансового коэффициента $i$ у организации $j ; X_{i e t}-$ эталонное значение финансового коэффициента $i$.

За эталонное значение возьмем лучшее значение данного показателя среди компаний, осуществляющих деятельность в аналогичных сферах: ООО «ПКФ ЭТ», ОАО «РЭП» и ОАО «КЭ». Будем оценивать привлекательность ООО «ПКФ ЭТ», являющегося поставщиком промышленного оборудования и производителя электрощитов. ОАО «РЭП» - одна из крупнейших специализированных инжиниринговых компаний России, выполняющая техническое обслуживание, ремонт, монтаж, реконструкцию, модернизацию и наладку электротехнического и тепломеханического оборудования и установок. ОАО «КЭ» - крупнейший российский производитель электротехнического оборудования широкого спектра. Для оценки привлекательности ООО «ПКФ ЭТ» за эталонные возьмем лучшие значения финансовых коэффициентов компаний. Соответствующие данные за 2015 год представлены в табл. 2.

По данным табл. 2 видно, что нет ни одной компании, все значения показателей которой являются эталонными. Эталонными коэффициентами $\mathrm{OAO}$ «РЭП» являются коэффициент текущей ликвидности $(1,3)$ и коэффициент оборачиваемости активов $(4,17)$. У компании ОАО «КЭ» эталоном является коэффициент рентабельности активов $(0,113)$; у компании ООО «ПКФ» - коэффициенты, характеризующие риски инвестора: запас финансовой прочности и сила операционного рычага. 
Таблица 2

Финансовые коэффициенты компаний, участвующих в расчете интегрального показателя инвестиционной привлекательности

\begin{tabular}{|l|c|c|c|c|}
\hline \multicolumn{1}{|c|}{ Показатель } & ОАО «РЭП» & ОАО «КЭ» & $\mathrm{OOO}$ «ПКФ» & Эталон \\
\hline Коэффициент текущей ликвидности & 1,30 & 1,12 & 0,94 & 1,30 \\
\hline Коэффициент автономии & 0,25 & 0,87 & 0,17 & 0,87 \\
\hline Коэффициент оборачиваемости активов & 4,17 & 0,04 & 2,19 & 4,17 \\
\hline Коэффициент рентабельности активов & 0,008 & 0,113 & 0,082 & 0,113 \\
\hline Запас финансовой прочности & 0,24 & $-0,3$ & 0,36 & 0,36 \\
\hline Сила операционного рычага & 4,19 & $-3,33$ & 2,8 & 2,8 \\
\hline
\end{tabular}

Расчет запаса финансовой прочности и силы операционного рычага, характеризующих риски инвестора при вложении средств, приведен в табл. 3.

Таблица 3

Расчет запаса финансовой прочности и силы операционного рычага компаний

\begin{tabular}{|l|c|c|c|}
\hline \multicolumn{1}{|c|}{ Показатель } & ОАО «РЭП» & ОАО «КЭ» & ООО «ПКФ» \\
\hline Выручка, тыс. руб. & 2263498 & 244855 & 56208 \\
\hline Переменные затраты, тыс. руб. & 1920976 & 59734 & 49162 \\
\hline Постоянные затраты, тыс. руб. & 260692 & 240739 & 4532 \\
\hline Точка безубыточности, тыс. руб. & 1722739 & 318419 & 36153 \\
\hline Валовая маржа, тыс. руб. & 342522 & 185121 & 7046 \\
\hline Прибыль от реализации, тыс. руб. & 81830 & -55618 & 2514 \\
\hline Запас прочности, \% & 23,89 & -30 & 35,68 \\
\hline Сила операционного рычага & 4,19 & $-3,33$ & 2,8 \\
\hline
\end{tabular}

На основании осуществленных расчетов соответствующих показателей были определены эталонные значения как максимальные среди трех фирмконкурентов. Так, запас финансовой прочности составил 0,36 против 0,24 (ОАО «РЭП) и отрицательного значения финансовой прочности ОАО «КЭ» $(-0,3)$. Сила операционного рычага составила 2,8 против 4,19 у ОАО «РЭП» (риск выше) и отрицательного значения $(-3,33)$ у компании ОАО «КЭ». Таким образом, по количеству эталонных коэффициентов невозможно однозначно выделить компанию, обладающую наибольшей инвестиционной привлекательностью. Поэтому далее необходимо осуществить расчет интегрального коэффициента. Он принимает следующие значения: у ОАО «РЭП» $K_{\text {ип }}=1,31$, у ОАО «КЭ» $K_{\text {ип }}=3,03$ и у ООО «ПКФ» $K_{\text {ип }}=1,01$. Рассчитанные коэффициенты инвестиционной привлекательности и ранжирование компаний представлены в табл. 4.

Согласно произведенным расчетам интегрального коэффициента инвестиционной привлекательности компаний-производителей электрооборудования наибольшей привлекательностью для инвестирования обладает ООО «ПКФ» 
$\left(K_{\text {ип }}=1,01\right.$ и первое место в рейтинговой оценке), компания ОАО «РЭП» $\left(K_{\text {ип }}=1,31\right.$ и второе место), ОАО «КЭ» обладает наименьшей привлекательностью $\left(K_{\text {ип }}=3,03\right.$ и третье место в рейтинговой оценке).

Таблица 4

Рейтинговая оценка привлекательности на основе расчета интегрального коэффициента инвестиционной привлекательности

\begin{tabular}{|l|c|c|}
\hline \multicolumn{1}{|c|}{ Наименование организации } & Значение коэффициента & Место в рейтинге \\
\hline ОАО «РЭП» & 1,31 & 2 \\
\hline OАО «КЭ» & 3,03 & 3 \\
\hline OОО «ПКФ» & 1,01 & 1 \\
\hline
\end{tabular}

Интересно отметить, что компания с меньшими объемами деятельности ООО «ПКФ» занимает первое место и обгоняет в рейтинговой оценке инвестиционной привлекательности более крупную компанию ООО «РЭП».

Использование данного метода позволяет максимально упростить процесс определения места предприятия среди подобных и выделить группы предприятий-лидеров, имеющих наилучшие показатели по результатам финансовой деятельности. Расчет в соответствии с предложенной методикой позволяет осуществлять оперативный мониторинг уровня инвестиционной привлекательности предприятий.

С другой стороны, так как инвестиционная привлекательность включает в себя достаточно широкий спектр факторов, отражающихся в значениях большого числа частных показателей, что, несомненно, может усложнить расчет интегрального показателя, наиболее полно отражающего уровень инвестиционной привлекательности анализируемого предприятия.

Недостатком данной методики для инвестора также может являться отсутствие видимости разности и инвестиционной привлекательности и рисков, что связано с тем, что числовые отклонения показателей между ними могут быть как незначительные, так и весьма ощутимые. Также инвестор не получает ответа на вопрос, какое значение $K_{\text {ип }}$ является достаточным, низким и высоким.

Более конкретную методику определения интегрального коэффициента инвестиционной привлекательности, в которой приведены также нормативные значения интегрального коэффициента, дает методика расчета кредитоспособности Сбербанка России. Эта методика основана на пяти финансовых коэффициентах, наиболее полно характеризующих финансовое состояние предприятия и его кредитоспособность: абсолютной ликвидности (К1), срочной ликвидности (К2), текущей ликвидности (К3), коэффициент соотношения собственных и заемных средств (К4), коэффициент рентабельности продаж (К5).

Результаты расчета коэффициентов и определение категории кредитоспособности для исследуемых предприятий за аналогичный период приведены в табл. 5 . 
Таблица 5

Определение категории кредитосопособности ООО «ПКФ»

\begin{tabular}{|c|l|c|c|c|c|}
\hline $\begin{array}{c}\text { № } \\
\text { п/п }\end{array}$ & \multicolumn{1}{|c|}{ Коэффициент } & $\begin{array}{c}\text { Расчетное } \\
\text { значение }\end{array}$ & Категория 1 & Категория 2 & Категория 3 \\
\hline 1 & Абсолютной ликвидности & 0,19 & 0,2 и выше & $0,15 \ldots 0,2$ & Менее 0,15 \\
\hline 2 & Срочной ликвидности & 0,61 & 0,8 и выше & $0,5 \ldots 0,8$ & Менее 0,5 \\
\hline 3 & Текущей ликвидности & 0,94 & 2,0 и выше & $1,0 \ldots 2,0$ & Менее 1,0 \\
\hline 4 & $\begin{array}{l}\text { Соотношение собственных } \\
\text { и заемных средств }\end{array}$ & 0,21 & 1,0 и выше & $0,7 \ldots 1,0$ & Менее 0,7 \\
\hline 5 & Рентабельности продаж & 0,03 & 0,15 и выше & Менее 0,15 & $\begin{array}{c}\text { Нерента- } \\
\text { бельный }\end{array}$ \\
\hline
\end{tabular}

На основании табличных данных рассчитаем сумму баллов $S$ (рейтинговое число): $S=0,11-2+0,05-2+0,42-3+0,21-3+0,21-2=2,63$.

Заемщик ООО «ПКФ» попадает в 3-й класс кредитоспособности, его кредитование связано с повышенным риском. Поэтому ООО «ПКФ» относится к предприятиям с низкой инвестиционной привлекательностью.

Анализ инвестиционной привлекательности проведен на примере предприятия, занимающегося производством и обслуживанием электрооборудования. Общую картину экономического состояния предприятия отразили основные технико-экономические показатели деятельности, которые характеризуют инвестиционную привлекательность предприятия как положительную. Выявлены следующие положительные тенденции: расширение деятельности и масштабов предприятия - рост выручки, активов, увеличение количества сотрудников и производительности труда, рост чистой прибыли. Однако если рассматривать инвестиционную привлекательность предприятия с точки зрения быстрого возврата средств и доходности, можно отметить слабые места: низкие показатели ликвидности, платежеспособности, снижение показателей рентабельности в ретроспективе. С другой стороны, с точки зрения рисков инвестора расчеты показали значительный запас финансовой прочности предприятия и лучшее значение силы операционного рычага, которые позволили занять первое место в рейтинге инвестиционной привлекательности среди компаний-конкурентов.

Однако анализ кредитоспособности по методике Сбербанка России показал, что предприятие не обладает достаточным уровнем привлекательности для банка как для инвестора.

Из недостатков данной методики можно отметить следующие:

1) не учитываются показатели, характеризующие риски инвестора при вложении средств;

2) «пересечение» показателей (несколько показателей ликвидности);

3) необоснованный подбор системы финансовых показателей;

4) не учитываются отраслевые особенности.

Учет большого числа критериев оптимальности при решении инвестиционных задач весьма целесообразен. На сегодняшний день ни один из известных 
показателей не способен отразить уровень достигнутых результирующих показателей функционирования предприятия. Поэтому при оценке инвестиционной привлекательности считаем целесообразным использовать комплекс методик, которые и всесторонне анализируют деятельность оцениваемого предприятия, и учитывают интересы всех субъектов инвестиционного процесса.

Исследование подготовлено при финансовой поддержке гранта РГНФ «Методика анализа и модель управления производственным и инвестиционнымм ииклами в рамках современного макроэкономического ичикла в экономике региона» № 17-12-59005.

\section{Список литературы}

1. Прибыткова Г. Методические подходы к оценке инвестиционной привлекательности как основы разработки инвестиционной политики // Инвестиции в России. - 2005. - № 3. - С. 3-13.

2. Ендовицкий Д., Бабушкин В. Сущность прямых иностранных инвестиций и характеристики привлекательности хозяйствующих субъектов для иностранных инвесторов [Электронный ресурс] // Инвестиции в России. - 2008. - № 3. - URL: http://economy-lib.com/find?q=\%D0\%91\%D0\%B0\%D0\%B1\%D1\%83\%D1\%88\% D0\%BA\%D0\%B8\%D0\%BD+\%D0\%92.\%D0\%90.\#ixzz4QzvyFyH2.

3. Федорович Т.В. Методические подходы к оценке инвестиционной привлекательности компании - цели слияния поглощения // Экономический анализ: теория и практика. - 2008. - № 6. - С. 29-31.

4. Северюгин Ю.В. Оценка инвестиционной привлекательности промышленного предприятия: автореф. дис. ... канд. экон. наук. - Ижевск, 2004. - 32 с.

5. Есипенко И.В. Формирование методики оценки инвестиционной привлекательности компании // Аудит и финансовый анализ. - 2011. - № 3. - С. 3-13.

6. Ендовицкий Д.А., Бабушкин В.А. Анализ капитализации публичной компании и оценка ее инвестиционной привлекательности // Экономический анализ: теория и практика. - 2009. - № 21. - С. 18-29.

7. Адамайтис Л.А., Агапитова Е.А. Применение сравнительной рейтинговой оценки в анализе инвестиционной привлекательности предприятия // Экономический анализ: теория и практика. - 2011. - № 41. - С. 27-34.

8. Чараева М.В. К вопросу о выборе методики оценки инвестиционной привлекательности предприятия // Финансы и кредит. - 2012. - № 14. - С. $34-40$.

9. Волков И.А. Адаптивность аттракторной модели привлечения инвестиционных средств // Дискуссия: журнал научных публикаций. - 2012. № 1 (19). - C. 61-66.

10. Поляков П.А. Комплексные подходы к оценке инвестиционной привлекательности компаний развивающихся стран на международных рынках // Управление экономическими системами: электрон. науч. журн. - 2012. - № 9. URL: http://uecs.ru/uecs45-452012/item/1556-2012-09-26-05-31-21. 
11. Бланк И.А. Основы инвестиционного менеджмента. - 2-е изд., перераб. и доп. - Киев: Эльга: Ника-Центр, 2004. - 660 с.

12. Ростиславов Р.А. Модель оценки инвестиционной привлекательности промышленного предприятия для стратегического инвестора // Известия Тульского государственного университета. Экономические и юридические науки. - 2011. - № 1-1. - С. 153-160.

13. Нурбаев Т.С. Теоретико-методические подходы к определению инвестиционной привлекательности компании. - Краснодар, 2012. - 247 с.

\section{References}

1. Pribytkova G. Metodicheskie podkhody k otsenke investitsionnoi privlekatel'nosti kak osnovy razrabotki investitsionnoi politiki [Methodical approaches to the assessment of investment attractiveness as the basis for investment policy development]. Investitsii v Rossii, 2005, no. 3, pp. 3-13.

2. Evdovitskii D., Babushkin V. Sushchnost' priamykh inostrannykh investitsii i kharakteristiki privlekatel'nosti khoziaistvuiushchikh sub"ektov dlia inostrannykh investorov [The essence of direct foreign investments and the characteristics of economic entities' attractiveness for foreign investors]. Investitsii v Rossii, 2008, no. 3, Available at: http://economy-lib.com/find?q=\%D0\%91\%D0\%B0\%D0\%B1\%D1\% 83\%D1\%88\%D0\%BA\%D0\%B8\%D0\%BD+\%D0\%92.\%D0\%90.\#ixzz4QzvyFyH2.

3. Fedorovich T.V. Metodicheskie podkhody $\mathrm{k}$ otsenke investitsionnoi privlekatel'nosti kompanii - tseli sliianiia pogloshcheniia [Methodical approaches to the assessment of company's investment attractiveness: merger purposes]. Ekonomicheskii analiz: teoriia i praktika, 2008, no. 6, pp. 29-31.

4. Severiugin Iu.V. Otsenka investitsionnoi privlekatel'nosti promyshlennogo predpriiatiia [Investment attractiveness assessment of an industrial enterprise]. Abstract of Ph. D. thesis. Izhevsk, 2004, p. 32.

5. Esipenko I.V. Formirovanie metodiki otsenki investitsionnoi privlekatel'nosti kompanii [Formation of a methodology for the company's investment attractiveness assessment]. Audit i finansovyi analiz, 2011, no. 3, vol. 1, pp. 3-13.

6. Endovitskii D.A., Babushkin V.A. Analiz kapitalizatsii publichnoi kompanii i otsenka ee investitsionnoi privlekatel'nosti [Analysis of a public company's capitalization and its investment attractiveness assessment]. Ekonomicheskii analiz: teoriia $i$ praktika, 2009, no. 21, pp. 18-29.

7. Adamaitis L.A., Agapitova E.A. Primenenie sravnitel'noi reitingovoi otsenki $\mathrm{v}$ analize investitsionnoi privlekatel'nosti predpriiatiia [The application of comparative rating in the analysis of a company's investment attractiveness]. Ekonomicheskii analiz: teoriia i praktika, 2011, no. 41, pp. 27-34.

8. Charaeva M.V. K voprosu o vybore metodiki otsenki investitsionnoi privlekatel'nosti predpriiatiia [On the issue of choosing a methodology for the company's investment attractiveness assessment]. Finansy i kredit, 2012, no.14, pp. 34-40. 
9. Volkov I.A. Adaptivnost' attraktornoi modeli privlecheniia investitsionnykh sredstv [The adaptability of the attractor model of investments attractions]. Politematicheskii zhurnal nauchnykh publikatsii "Diskussiia", 2012, no. 1, vol. 19, pp. 61-66.

10. Poliakov P.A. Kompleksnye podkhody k otsenke investitsionnoi privlekatel'nosti kompanii razvivaiushchikhsia stran na mezhdunarodnykh rynkakh [Comprehensive approaches to the assessment of companies' investment attractiveness in developing countries at international markets]. Upravlenie ekonomicheskimi sistemami, 2012, no. 9. Available at: http://uecs.ru/uecs45-452012/item\1556-2012-09-26-05-31-21.

11. Blank I.A. Osnovy investitsionnogo menedzhmenta [Basic concepts of investment management]. 2nd ed. revised and corrected. Kiev, El'ga, Nika-Tsentr Publ., 2004, 660 p.

12. Rostislavov P.A. Model' otsenki investitsionnoi privlekatel'nosti promyshlennogo predpriiatiia dlia strategicheskogo investora [Assessment model of an industrial enterprise investment attractiveness for a strategic investor]. Izvestiia Tul'skogo gosudarstvennogo universiteta. Ekonomicheskie i iuridicheskie nauki, 2011, no. 1, vol. 1, pp. 153-160.

13. Nurbaev T.S. Teoretiko-metodicheskie podkhody k opredeleniiu investitsionnoi privlekatel'nosti kompanii [Theoretical and methodological approaches to determining a company's investment attractiveness]. Krasnodar, 2012, 247 p.

Оригинальность статьи - $76 \%$

Получено 28.11.2016

O.V. Butorina, I.V. Shishkina

THE COMPANY'S INVESTMENT ATTRACTIVENESS: ESSENCE AND COMPARISON OF ASSESSMENT METHODS

The article presents the author's definition of the term company's investment attractiveness and defines the methods of its analysis in the Russian and foreign theory and practice of investment management. Having compared fifteen analytical methods of investment attractiveness, the authors define the indicators of qualitative and quantitative assessment, as well as their benefits and drawbacks from the point of view of external and internal conditions of companies' functioning in modern Russia. Certain conclusions can be drawn after testing the most particular methods that correspond with the calculations of companies producing electrical equipment. These include the necessity of using integrated methods, expediency of calculating integrated index of investment attractiveness as a resulting parameter of investment decision making, relevance of using these methods in control values calculation, the need for adjustment and supplementing the qualitative and quantitative indicators that characterize the basic companies' activities in dynamics, as well as inclusion of all the participants of integration activity. Despite their ambivalence, research findings can be applied in theory and practice of investment attractiveness management in companies and regions.

Keywords: investment attractiveness, companies' investment attractiveness, external and internal factors of companies' investment attractiveness, comparison of assessment methods of companies' investment attractiveness, company's integrated index of investment attractiveness.

Oksana V. Butorina - Candidate of Economic Sciences, Associate Professor, Dept. of Economics and Finance, Dept. of Global and Regional Economics, Economic Theory, Perm National Research Polytechnic University, e-mail: ok.butorina@yandex.ru.

Irina V. Shishkina - Senior Lecturer, Dept. of Global and Regional Economics, Economic Theory, Perm National Research Polytechnic University, e-mail: irvik-59@mail.ru.

PNRPU Sociology and Economics Bulletin. 2017. No. 2 